\title{
Serenoa repens extracts: In vitro study of the $5 \alpha$-reductase activity in a co-culture model for Benign Prostatic Hyperplasia
}

\author{
Daniela Buonocore ${ }^{1}$, Manuela Verri ${ }^{1}$, Laura Cattaneo ${ }^{1}$, Sara Arnica ${ }^{1}$, Michele Ghitti ${ }^{2}$, \\ Maurizia Dossena ${ }^{1}$ \\ ${ }^{1}$ University of Pavia, Pavia (Italy), Department of Biology and Biotechnology "L. Spallanzani"; \\ ${ }^{2}$ University of Pavia, Pavia (Italy), Department of Earth and Environmental Sciences (DSTA) - Unit of Statistical Analyses \\ (UNISTAT).
}

\begin{abstract}
Summary Objectives. Benign Prostatic Hyperplasia $(B P H)$ is a form of benign tumor that occurs in humans mainly with ageing. It affects more than $50 \%$ of over 50 years old males and it is characterized by an increased synthesis of dihydrotestosterone (DHT), due to the $5 \alpha$-reductase activity. The BPH therapentic approach mainly uses $5 \alpha$-reductase inhibitors, such as the active compounds present in the extracts deriving from species Serenoa repens. Many lipidosterolic extracts are available on the market, which are obtained with different solvents, among them ethanol is recognized as non-toxic and has less handling risks than hexane. The purpose of the present experimental study was to investigate in-vitro the potency of an ethanol extract of S. repens comparing it with an n-hexane one.

Materials and methods. Two different lipido-sterolic extracts of S. repens have been tested: ethanol extract and $n$-hexane extract, two batches for each one. The inhibitory action of the extract was evaluated estimating in-vitro the activity of enzyme $5 \alpha$-reductase type I ( $5 \alpha-R I)$, which was mainly active under the experimental condition of $\mathrm{pH}$ 7.5. DHT amount, synthesized from testosterone $(1 \mu \mathrm{M})$, was evaluated in a co-culture model of epithelial cells and fibroblasts resulting from prostatic biopsy of a patient with BPH.

Results. The analysis of the resulting dose-response curves showed that the entire S. repens extracts inhibited the $5 \alpha-R I$ showing no difference between the two kinds of extract or between the batches. The resulting IC50 values were the following: 8.809 (95\% CI $=5.133-15.56)$ and $9.464(95 \% C I=5.094$ 18.27) for ethanol extracts; $11.08(95 \% C I=6.389-19.98)$ and $12.72(95 \% C I=7.758-21.53)$ for $n$-hexane extracts.

Conclusions. The potency of ethanol extracts of S. repens was comparable with the one of n-hexane extracts.
\end{abstract}

KEY WORDS: Benign Prostatic Hyperplasia; Dihydrotestosterone; Ethanol extracts; In-vitro study; $5 \alpha$-reductase; Serenoa repens.

Submitted 7 May 2018; Accepted 12 July 2018

\section{INTRODUCTION}

Benign Prostatic Hyperplasia (BPH) is a form of benign tumor that occurs in humans mainly with ageing. In fact, it affects more than $50 \%$ of over 50 years old males, with an incidence rate directly proportional to age (1). It is characterized by an increased synthesis of dihydrotestosterone (DHT) starting from testosterone, due to the action of enzyme 5 $\alpha$-reductase, which leads to an increase of the prostate size and causes various disorders, especially in the lower urinary tract $(1,2)$. The approach for the treatment and therapy of BPH is mainly based on the use of inhibitors of $5 \alpha$-reductase enzyme, in particular natural inhibitors, such as the active compounds present in the alcoholic extracts deriving from species Serenoa repens, a typical palm common in the Subtropical sandy soils and in the southern coasts of the United States. Although the sure mechanism of action of S. repens is not yet fully understood, numerous mechanisms have been proposed (3) and the presence of specific fatty acids (saturated and unsaturated fatty acids) and phytosterols in its alcoholic extracts confers upon $S$. repens an anti-inflammatory and above all antiproliferative action on prostatic tissue (4). Both a systematic Cochrane review of the literature (5) and a meta-analysis (6) assessed the safety profile and the clinical efficacy of S. repens in the treatment of symptoms in patients with $\mathrm{BPH}$. These studies have shown an improvement of urinary tract disorders, with a mild to moderate effect and, therefore, a lack of therapeutic equivalence between $S$. repens extracts of different brands and between extracts of a single brand, but belonging to different manufacturing batches $(5,6)$. Many lipido-sterolic extracts are commercially available, which were obtained with different solvents, among them ethanol is recognized as non-toxic and it has less handling risks than hexane $(7,8)$. The purpose of the present experimental study was to investigate in-vitro the potency of an ethanol extract of $S$. repens comparing it with an $\mathrm{n}$-hexane one. In particular, the activity of enzyme $5 \alpha$-reductase was estimated invitro concerning the inhibitory action of the extracts, using co-cultures of epithelial cells and fibroblasts resulting from prostatic biopsy of a patient with $\mathrm{BPH}$.

\section{MATERIALS AND METHOdS}

\section{Samples}

Two extracts, belonging to commercial brands $S A B A^{\circledR}$ (Lampugnani Farmaceutici) and PERMIXON ${ }^{\circledR}$ (Pierre Fabre Pharma), supplied with marketing authorization in 
several EU Member States (including Italy) and belonging to the class of drugs employed to counter the increase in prostatic volume in males with $\mathrm{BPH}$, have been tested. The two branded drugs contained the lipid-sterolic extract of S. repens (320 mg/soft capsule) as active ingredient and particularly, ethanol extract $\left(S A B A^{\circledR}\right)$ and hexane extract (PERMIXON ${ }^{\circledR}$ ). Two different batches of each brand were tested: SABA ${ }^{\circledR}$ (G08363 and G08364); PERMIXON $^{\circledR}$ (F 11917 and G07340), mentioned below as "samples".

The content of one soft capsule was weighed $(10 \mathrm{mg})$ and dissolved in $\mathrm{N}$-hexane; then the solvent was evaporated to leave the solid extract that was dissolved in ethanol $(70 \%)$ to give a concentration of $10 \mathrm{mg} / \mathrm{ml}$.

This stock solution was further diluted in appropriate media to provide a working solution of $1 \mathrm{mg} / \mathrm{ml}$ (9).

\section{Co-culture cell model}

Two types of primary cells were used: epithelial cells and fibroblasts, previously isolated from prostatic tissue obtained during a biopsy from a patient with established $\mathrm{BPH}$. Informed consent of the patient was obtained. Primary cultures of fibroblast and epithelial cells were obtained as previously described (2). Both the epithelial and fibroblast cells were cultured separately in flasks with culture medium, complete with fetal bovine serum (10\%), DMEM and RPMI 1640 respectively, and kept in an incubator in a humidified atmosphere $\left(37^{\circ} \mathrm{C}\right.$ and $5 \%$ $\mathrm{CO}_{2}$ ). Corresponding to the third generation step, both the epithelial cells and fibroblasts, were transferred into multiwell plates of 12 wells provided with Transwell $^{\circledR}$ (3470 Clear-Corning), or supports consisting of a microporous polystyrene membrane. This enabled to keep the two cell populations separate but, at the same time, to allow their interactions.

In particular: epithelial cells were sown in the number of 50,000 on the bottom of each well; on the contrary, fibroblasts were sown in the number of 5,000 on the microporous polystyrene membrane. Co-cultures were maintained in DMEM:RPMI-1640 (1:1 v/v) media + 10\% fetal calf serum at $37^{\circ} \mathrm{C}$ in $5 \% \mathrm{CO}_{2}(10)$.

Furthermore, in order to verify that the fibroblasts were correctly adhering to the membrane, the quantitative technique TEER (Transepithelial Transendothelial Electrical Resistance) was applied; this technique enabled to examine the integrity of the cell junctions (tight junctions) by measuring the resistance that the monolayer of fibroblasts opposed to the passage of electric current (11).

Measurement of the trans-epithelial resistance value, expressed in Ohms and normalized for the polystyrene membrane area $\left(\Omega / \mathrm{cm}^{2}\right)$, was performed using a voltmeter (Millicell ${ }^{\circledR}$ ERS-2, Merck Millipore) equipped with two electrodes of different length (data not reported).

\section{$5 \alpha$-reductase activity assay}

The co-culture cells were pre-treated for a period of four days with a non-toxic concentration $(10 \mu \mathrm{g} / \mathrm{ml})$ of each sample (SABA ${ }^{\circledR}$ : G08363 and G08364; PERMIXON ${ }^{\circledR}$ : F 11917 and G07340). Afterwards the cells were harvested by trypsinization, centrifuged and the pellet was suspended in RPMI-1640, supplemented with $10 \%$ fetal calf serum, and then counted. The $\mathrm{pH}$ value of the medium solution was 7.85, an optimum value for the activity of 5 $\alpha$-reductase type I (12). Cell suspensions were added into tubes containing testosterone $(1 \mu \mathrm{M})$ as substrate, a NADPH-regenerating system $(0.5 \mathrm{mM}$ glucose-6-phosphate, $0.06 \mathrm{U}$ glucose-6-phosphate dehydrogenase, $50 \mu \mathrm{M}$ $\mathrm{NADPH})(\mathrm{H}+$ donor) (13) and different concentrations of each sample: $1 \mathrm{mg} / \mathrm{ml}, 100 \mu \mathrm{g} / \mathrm{ml}, 10 \mu / \mathrm{ml}, 5 \mu \mathrm{g} / \mathrm{ml}, 1$ $\mu \mathrm{g} / \mathrm{ml}, 0.1 \mu \mathrm{g} / \mathrm{ml}, 0.01 \mu \mathrm{g} / \mathrm{ml}$; these concentrations were chosen basing on the cytotoxicity results, previously obtained in laboratory applying the MTT test (14)) and in agreement with data present in the literature $(9,10)$.

The tubes were then incubated at $37^{\circ} \mathrm{C}$ for $30 \mathrm{~min}$ in a stirring water bath. The reaction was stopped by dipping the tubes into liquid nitrogen $(9,10,12)$.

The $5 \alpha$-reductase type I activity was assessed by measuring the conversion of testosterone to dihydrotestosterone (DHT) applying a qualitative/quantitative Enzyme-Linked Immunosorbent Assay (Abnova KA1886), as previously described (15).

Enzyme activity is expressed as a percentage of the control. The conversion of $1 \mu \mathrm{M}$ of testosterone in the absence of inhibitors is defined as 100\% activity (2.95$3.63 \mathrm{nmol}$ of DHT/106 cells/min for type I isoenzyme). Dose-effect response curves were analyzed using a sigmoid maximum-effect model with a variable slope (Graphpad, Prism7).

Inhibitory potency was assessed by estimating the IC50 value that represented the concentration $(\mu \mathrm{g} / \mathrm{ml})$ capable of determining the $50 \%$ of the maximal effect (enzymatic inhibition). The highest IC50 value was then divided by the IC50 values obtained for each sample for the relative potency (RP) (the relative potency value $=1$ was considered the lowest value).

\section{Statistical analysis}

The nonlinear-regression curves were analyzed applying two different Linear Mixed Models, one to analyze the commercial brands $\left(S A B A^{\circledR}\right.$ vs PERMIXON $\left.{ }^{\circledR}\right)$ and one for the batches. The analyses were performed with software R.

\section{Results}

All the samples of S. repens extracts (F 11917; G07340; G08363; G08364) were found to be capable of inhibiting $5 \alpha$-reductase $(5 \alpha-R I)$ in a prostatic co-cultured epithelial and fibroblast cells, as shown by dose-effect curves in Figure 1 (enzyme activity (\%) as a function of the logarithm of concentrations).

Regarding the potency of each sample, evaluated by IC50 value (Table 1) and highlighted by the relative potency (Table 2), SABA ${ }^{\circledR}($ IC50 $=8.809$ and 9.464) showed a higher efficacy on $5 \alpha$-RI than PERMIXON ${ }^{\circledR}$ (IC50 $=11.08$ and 12.72), but there were non-significant differences between the two brands and batches, as mentioned below.

Regarding the comparison between the two brands $\left(S A B A^{\circledR}\right.$ vS PERMIXON ${ }^{\circledR}$ ), the analysis of deviance (Type III tests) for $5 \alpha$-RI data set showed that the model was non-significant (Response: enzyme; Chisq Df $\operatorname{Pr}$ (>Chisq); (Intercept) 28.360011 .007 -07 ***; Brand 2.92281 0.08734 ; Signif. codes: 0 '*** $0.001^{(* *)} 0.011^{\prime *} 0.05$ '? 0.1 "'1). 


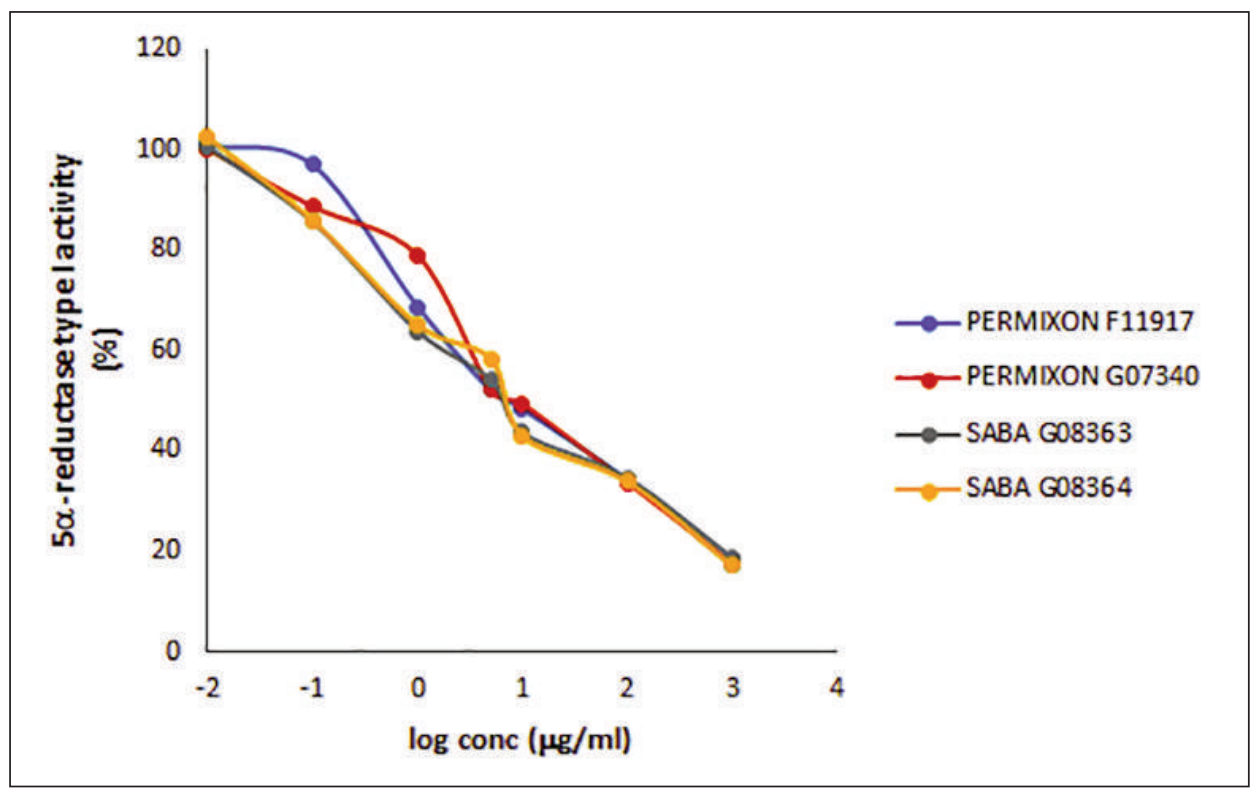

Figure 1.

Inhibition of

$5 \alpha$-reductase type I.

Enzyme activity, depending on the logarithm of concentrations, is expressed in percentage as compared with the positive control (100\% of enzyme activity converting testosterone $1 \mu \mathrm{M}$, in the absence of inhibitors).
Regarding the comparison between the batches (F 11917; G07340; G08363; G08364), the analysis of deviance (Type III tests) showed that the model was non-significant [Response: enzyme; Chisq Df $\operatorname{Pr}$ (> Chisq); (Intercept) $28.017611 .202 \mathrm{e}-07 * * *$; Batch 2.93263

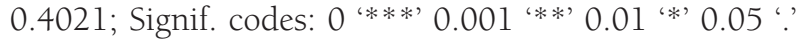
0.1 ' 1 ].

Regarding the relative potency (Table 2), both $S A B A^{\circledR}$ and PERMIXON ${ }^{\circledR}$ showed comparable potencies between the two batches and PERMIXON ${ }^{\circledR}$ showed the lowest values.

\section{Discussion}

All the extracts of $S$. repens that we tested, $S A B A^{\circledR}$ (G08363 and G08364) and PERMIXON ${ }^{\circledR}$ (F 11917 and

Table 1.

Comparative potency of the two extracts on $5 \alpha$-reductase type I, given by IC50 value and related $95 \% \mathrm{Cl}$.

\begin{tabular}{|lcccc|}
\hline & \multicolumn{2}{c}{ PERMIXON } & \multicolumn{2}{c|}{ SABA } \\
& F11917 & G07340 & G08363 & G08364 \\
\hline $\mathrm{IC50}(5 \alpha-\mathrm{RI})^{1}$ & 11.08 & 12.72 & 8.809 & 9.464 \\
\hline $95 \% \mathrm{Cl}{ }^{2}$ & 6.39 to 19.98 & 7.76 to 21.53 & 5.13 to 15.56 & 5.09 to 18.27 \\
\hline $15 \alpha-$-Rl: $5 \alpha$-reductase type l. ${ }^{2} \mathrm{Cl}:$ Confidence Interval. & & \\
\hline
\end{tabular}

Table 2.

Relative potency of the various extracts on $5 \alpha$-reductase type I (considering $R P=1$ as the lowest potency).

\begin{tabular}{|c|c|c|c|c|}
\hline & \multicolumn{4}{|c|}{$5 \alpha-\left.R\right|^{1}$} \\
\hline & SABA & SABA & PERMIXON & PERMIXON \\
\hline$\overline{\text { Batch }}$ & G08363 & G08364 & F11917 & G07340 \\
\hline$\overline{\mathrm{RP}^{2}}$ & 1.444 & 1.344 & 1.148 & 1 \\
\hline
\end{tabular}

G07340), have shown to inhibit enzyme $5 \alpha$-reductase in a co-culture model of human prostatic cells (epithelial and fibroblasts), as reported also in the literature $(9,10)$. Even though the potency of SABA samples of inhibiting the activity of enzyme $5 \alpha$-reductase type I showed higher values than PERMIXON's values, there were no significant statistical differences between the two brands or the batches. These in-vitro results pointed out that the $S$. repens ethanol extract $\left(S A B A^{\circledR}\right)$ was equivalent to the nhexane one (PERMIXON $\left.{ }^{\circledR}\right)$.

This conclusion is important because basing on the equivalence of efficacy for both tested extracts, obtained with different extraction methods, it would be better to use organic solvents (ethanol) recognized as environmentally safer and alternative to hexane, which is a solvent obtained from petrochemical sources that can remain in potential traces in edible oils after refining and can be emitted during extraction and recovery and that has been identified as an air pollutant since it can react with other pollutants to produce ozone and photochemical oxidants $(7,8,16)$.

Moreover, data that we obtained allow us to speculate on the possible effects of the ethanol extract from S. repens on the pathology of BPH: it is known that clinical benefits are generally associated with the free fatty acid content, along with a small contribution from unsaponifiable components $(17,18)$.

Particularly, the relative inhibitory efficacy of the various free fatty acids seems to depend on the length of the carbon chain and its saturation state (17). For example, lauric acid (short saturated, C12 chain) inhibits both 5 $\alpha$-reductase type I and II, while oleic acid with a C18 unsaturated chain (C18 $\Delta 9)$ and linoleic acid (C18 $\Delta 9,12)$ have a good activity on type I but not on type II (15). SABA ${ }^{\circledR}$ and PERMIXON ${ }^{\circledR}$ (19) were analyzed in 
terms of concentration in free fatty acids, methyl and ethyl esters, long-chain esters and glycerides. These analyses revealed that each of the individual FFAs analyzed was found in similar proportions in the tested products, with lauric and oleic acids present at the highest concentrations in every tested sample and similar concentrations of methyl and ethyl esters were found. Instead, glyceride content was particularly high (420\%) in $S A B A^{\circledR}$ and not in PERMIXON ${ }^{\circledR}$.

Generally, a similar content composition was observed between $S A B A^{\circledR}$ and PERMIXON ${ }^{\circledR}$ (19). So, our results are explained by data reported above: similar content composition is associated with the same potency of ethanol and hexane extracts.

\section{Conclusions}

Ethanol extract of $S$. repens has shown in vitro a potency of inhibiting the activity of enzyme $5 \alpha$-reductase comparable with potency of $n$-hexane extract of S. repens.

\section{REFERENCES}

1. Ryt A, Rotter I, Grzywacz A, et al. Molecular analysis of the SRD5A1 and SRD5A2 genes in patients with benign prostatic hyperplasia with regard to metabolic parameters and selected hormone levels. Int J Environ Res Public Health. 2017; 14:1318.

2. Bayne CW, Donnely F, Chapman K, et al. A Novel coculture model for benign prostatic hyperplasia expressing both isoforms of 5a-reductase. JCEM. 1998; 83:206.

3. Buck AC. Is there a scientific basis for the therapeutic effects of Serenoa repens in benign prostatic hyperplasia? Mechanisms of action. J Urol. 2004; 172:1792.

4. Capasso F, De Pasquale R, Grandolini G. Droghe contenenti lipidi. In: Farmacognosia. Botanica, chimica e farmacologia delle piante medicinali. Italia: Ed. Springer Verlag, 2014.

5. Wilt T, Ishani A, MacDonald R. Serenoa repens for benign prostatic hyperplasia. Cochrane Database Syst Rev. 2002; CD001423.

6. Boyle P, Robertson C, Lowe F, Roehrborn C. Updated metaanalysis of clinical trials of Serenoa repens extract in the treatment of symptomatic benign prostatic hyperplasia. BJUI. 2004; 39:751.
7. Johnson LA \& Lusas EW. Comparison of alternative solvents for oils extraction. J Am Oil Chem Soc. 1983; 60:229.

8. Ferreira-Dias S, Valente DG, Abreu JMF. Comparison between ethanol and hexane for oil extraction from Quercus suber $L$. fruits. Grasas y Aceites. 2003; 54:378.

9. Scaglione F, Lucini V, Pannacci $M$, et al. Comparison of the Potency of Different Brands of Serenoa repens Extract on $5 \alpha$ Reductase Types I and II in Prostatic Co-Cultured Epithelial and Fibroblast Cells. Pharmacology. 2008; 82:270.

10. Bayne CW, Donnely F, Ross M, Habib FK. Serenoa repens (Permixon $\left.{ }^{\circledR}\right)$ : A $5 \alpha$-reductase Types I and II Inhibitor-New evidence in a Coculture Model of BPH. Prostate. 1999; 40:232.

11. Srinivasan B, Kolli Reddy A, Esch MB, et al. TEER measurement techniques for in vitro barrier model systems. J Lab Autom. 2015; 20:107.

12. Smith CM, Ballard SA, Worman N, et al. 5 alpha-reductase expression by prostate cancer cell lines and benign prostatic hyperplasia in vitro. J Clin Endocrinol Metab. 1996; 81:1361.

13. Weisser H, Tunn S, Behnke B, Krieg M. Effects of the sabal serrulata extract IDS 89 and its subfractions on 5 alpha-reductase activity in human benign prostatic hyperplasia. Prostate. 1996; 28:300.

14. Mosmann T. Rapid colorimetric assay for cellular growth and survival: application to proliferation and cytotoxicity assays. J Immunol Methods. 1983; 65:55.

15. Di Silverio F, D'Eramo G, Lubrano C, et al. Evidence that Serenoa repens extract displays an antiestrogenic activity in prostatic tissue of benign prostatic hypertrophy patients. Eur Urol. 1992; 21:309.

16. Wan PJ, Pakarinen DR, Hron RJSr, et al. Alternative hydrocarbon solvents for cottonseed extraction. J Am Oil Chem Soc. 1995; 72:653.

17. Paubert-Braquet M, Cousse H, Raynaud JP, et al. Effects of the lipido-sterolic extract of Serenoa repens (Permixon ${ }^{\circledR}$ ) and its major components on basic fibroblast growth factor-induced proliferation of cultures of human prostate biopsies. Eur Urol. 1998; 33:340.

18. Raynaud JP, Cousse H, Martin PM. Inhibition of type 1 and type 25 alpha-reductase activity by free fatty acids, active ingredients of Permixon ${ }^{\circledR}$. J Steroid Biochem Mol Biol. 2002; 82:233.

19. Habib FK \& Wyllie MG. Not all brands are created equal: a comparison of selected components of different brands of Serenoa repens extract. Prostate Cancer Prostatic Dis. 2004; 7:195.

\section{Correspondence}

Daniela Buonocore, MD (Corresponding Author)

daniela.buonocore@unipv.it

Manuela Verri, MD

manuela.verri@unipv.it

Laura Cattaneo, MD

laura.cattaneo02@universitadipavia.it

Sara Arnica, MD

sara.nica90@gmail.com

Maurizia Dossena, MD

maurizia.dossena@unipv.it

Via Ferrata, 9-27100 Pavia, Italy

Michele Ghitti, MD

ghitti.michele@gmail.com

Via Ferrata, 1-27100 Pavia, Italy 